\title{
Volume-staged versus dose-staged radiosurgery outcomes for large intracranial arteriovenous malformations
}

\author{
Shayan Moosa, B.A., ${ }^{1}$ Ching-Jen Chen, M.D., ${ }^{1}$ Dale Ding, M.D., ${ }^{1}$ Cheng-Chia Lee, M.D., 2 \\ Srinivas Chivukula, M.D., ${ }^{3}$ Robert M. Starke, M.D., M.Sc., ${ }^{1}$ Chun-Po Yen, M.D., ${ }^{1}$ \\ Zhiyuan Xu, M.D., ${ }^{1}$ AND Jason P. Sheehan, M.D., Ph.D. ${ }^{1}$ \\ ${ }^{1}$ Department of Neurological Surgery, University of Virginia Health System, Charlottesville, Virginia; \\ ${ }^{2}$ Department of Neurosurgery, Neurological Institute, Taipei Veterans General Hospital, Taipei, Taiwan; and \\ ${ }^{3}$ Department of Neurological Surgery, University of Pittsburgh Medical Center, Pittsburgh, Pennsylvania
}

\begin{abstract}
Object. The aim in this paper was to compare the outcomes of dose-staged and volume-staged stereotactic radiosurgery (SRS) in the treatment of large $\left(>10 \mathrm{~cm}^{3}\right)$ arteriovenous malformations (AVMs).

Methods. A systematic literature review was performed using PubMed. Studies written in the English language with at least 5 patients harboring large $\left(>10 \mathrm{~cm}^{3}\right)$ AVMs treated with dose- or volume-staged SRS that reported posttreatment outcomes data were selected for review. Demographic information, radiosurgical treatment parameters, and post-SRS outcomes and complications were analyzed for each of these studies.

Results. The mean complete obliteration rates for the dose- and volume-staged groups were $22.8 \%$ and $47.5 \%$, respectively. Complete obliteration was demonstrated in 30 of $161(18.6 \%)$ and 59 of $120(49.2 \%)$ patients in the dose- and volume-staged groups, respectively. The mean rates of symptomatic radiation-induced changes were $13.5 \%$ and $13.6 \%$ in dose- and volume-staged groups, respectively. The mean rates of cumulative post-SRS latency period hemorrhage were $12.3 \%$ and $17.8 \%$ in the dose- and volume-staged groups, respectively. The mean rates of post-SRS mortality were $3.2 \%$ and $4.6 \%$ in dose- and volume-staged groups, respectively.

Conclusions. Volume-staged SRS affords higher obliteration rates and similar complication rates compared with dose-staged SRS. Thus, volume-staged SRS may be a superior approach for large AVMs that are not amenable to single-session SRS. Staged radiosurgery should be considered as an efficacious component of multimodality AVM management.
\end{abstract}

(http://thejns.org/doi/abs/10.3171/2014.5.FOCUS14205)

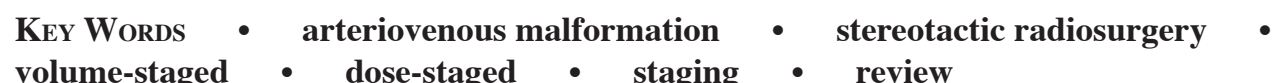

$\mathrm{T}$ IhE management of large $\left(>10 \mathrm{~cm}^{3}\right)$ arteriovenous malformations (AVMs) is both challenging and controversial. There are high rates of morbidity and mortality for microsurgical interventions, ${ }^{20-22,45}$ and curative embolization can also be difficult and unsafe..$^{53}$ Stereotactic radiosurgery (SRS) has proven beneficial in the treatment of small- and moderately sized AVMs with resulting high obliteration rates..$^{14,15,34}$ However, large and high-grade AVMs continue to present management challenges due to their lower obliteration rates and longer latent periods to achieving obliteration..$^{13,38,53}$ The obliteration rate is directly related to the total radiation dose used to treat the AVM.$^{17}$ However, treating large AVMs with traditional effective doses of radiation results in increased risk of adverse radiation effects on surrounding

Abbreviations used in this paper: $\mathrm{AVM}=$ arteriovenous malformation; GKRS = Gamma Knife radiosurgery; HSRT = hypofractionated stereotactic radiotherapy; RIC = radiation-induced change; SRS $=$ stereotactic radiosurgery . brain tissue. Consequently, single-session SRS for larger AVMs can exhibit a higher rate of complications, which include radiation necrosis, cyst formation, hemorrhage, cerebral edema, and worsening neurological deficits or seizures. ${ }^{17,36,38}$

More recent treatment strategies for large AVMs involve the delivery of radiation doses in stages with dose- or volume-staged SRS. Dose staging is described in the literature as either hypofractionated stereotactic radiotherapy (HSRT) or repeat SRS. Hypofractionated stereotactic radiotherapy is typically performed by administering several small doses of radiation to the AVM over a period of a few weeks. Repeat radiosurgery uses a higher initial dose (yet still lower than traditional single-session SRS for small to moderate AVMs), and another dose is administered after several months or years if there is no evidence of obliteration. In volume-staged SRS, distinct geometrical portions of the AVM are treated over time until the entire AVM is irradiated. Both dose- and volume-staged SRS are used to facilitate obliteration while reducing complication rates for 


\section{S. Moosa et al.}

large AVMs. The purpose of this study is to examine reports in the literature to date to determine the efficacy and risks of dose- and volume-staged SRS.

\section{Methods}

\section{Inclusion Criteria}

Studies for this systematic review were selected based on the following criteria: 1) The study must include at least 5 patients with cerebral AVMs treated with dosestaged or volume-staged SRS. 2) The mean volume of AVMs in the study must be greater than or equal to 10.0 ml. 3) The study must include posttreatment outcomes data. 4) The language of the study must be English. Studies pertaining to repeat SRS for AVMs or radiosurgery for other types of cerebrovascular lesions were excluded from this analysis.

\section{Literature Search}

A systematic review of the literature was performed using PubMed and the following search term: "arteriovenous malformation AND radiosurgery OR radiotherapy AND stage OR staged OR staging OR hypofractionated OR fraction OR fractionated OR fractionation." A filter was used to only return articles written in the English language. This search yielded 212 articles from 1985 to 2014, which were further screened based on the inclusion criteria above using the title and abstracts of the search results. Twenty-six articles were then selected, among which 11 were excluded from the analysis due to insufficient follow-up time (less than 24 months), overlapping data from previous studies, reporting of actuarial obliteration rates without clear indication of exact number of AVMs obliterated at the end of the follow-up period, and inadequate specification of staging methods. The remaining 15 studies were subsequently classified by staging method, yielding 8 series $^{7,29,32,33,42,48,51,54}$ comprising 234 patients treated with HSRT and 7 series $^{2,5,10,23,26,31,43}$ comprising 167 patients treated with volume-staged SRS. Figure 1 is a flowchart depicting the systematic review process.

\section{Literature Review and Data Extraction}

Information relating to patient demographics, radiosurgical treatment parameters, and post-SRS outcomes and complications were recorded from the 15 studies that met the inclusion criteria. Whenever possible, we gathered specific demographic information from each study, including the total number of patients, sex, mean age, mean AVM volume, Spetzler-Martin classification, clinical presentation, history of previous hemorrhage, history of previous embolization, and mean follow-up duration. Variables pertaining to radiosurgical methodology included mean total dose (dose-staged studies), mean margin dose (volume-staged studies), isodose line, number of stages, and time elapsed between stages. For post-SRS outcomes and complications, recorded data included the number and percentage of posttreatment patients demonstrating angiographic or other imaging evidence of complete or partial obliteration, mean time to obliteration, and number and percentage of patients with radiation-induced changes (RICs), hemorrhage, and death from treatment. Radiation-induced changes were defined as imaging findings of edema, cyst formation, or necrosis correlated with patient-reported symptoms or worsening of neurological deficits or seizures as a result of radiation treatment.

\section{Statistical Analysis}

Statistical analysis in this review was performed using SPSS Statistics (version 22.0.0.0, IBM Corp.). Descriptive statistics were obtained for complete obliteration rate, partial obliteration rate, RIC rate, hemorrhage rate, and mortality rate in both the dose- and volume-staged groups.

\section{Results}

\section{Overall Demographics and Treatment Characteristics}

From the 15 studies meeting the inclusion criteria, 123 of 218 patients with follow-up in the dose-staged group (56.4\%) and 69 of 152 patients with follow-up in the volume-staged group (45.4\%) were female. The mean age ranged from 34 to 43 years in the dose-staged group and 26 to 37 years in the volume-staged group. Linear accelerator (LINAC)-based therapy was used as the treatment modality in 6 of the 8 dose-staged series (75\%). The mean total dose for the dose-staged group ranged from 20 to 42 Gy delivered in 2-12 stages with at least 1 day between each fraction. Gamma Knife radiosurgery (GKRS) was used as the treatment modality in all 7 of the volumestaged series. The mean margin dose for the volumestaged group ranged from 15 to 20.8 Gy delivered to each volumetric component with the total AVM being treated in 2-4 stages with time intervals of 1-9 months between each fraction. Prior hemorrhages were reported in 90 of $197(45.7 \%)$ patients and 72 of $152(47.4 \%)$ patients in the dose- and volume-staged groups, respectively. Prior endovascular embolization was performed in 72 of $143(50.3 \%)$ patients and 51 of $147(34.7 \%)$ patients in the dose- and volume-staged groups, respectively. Summaries of patient and treatment characteristics for the dose- and volumestaged series are presented in Tables 1 and 2, respectively.

\section{Obliteration Rates}

Obliteration in studies was defined as absence of the AVM seen on cerebral angiography and/or MRI. The mean complete obliteration rate for the dose-staged group was $22.8 \%$ (95\% CI 4.4\%-41.1\%), with follow-up periods ranging from 29 to 102 months. The mean complete obliteration rate for the volume-staged group was $47.5 \%(95 \%$ CI $34.3 \%-60.8 \%$ ), with follow-up periods ranging from 28 to 87 months. Complete obliteration was demonstrated in 30 of $161(18.6 \%)$ patients with sufficient follow-up in the 8 dose-staged studies and 59 of $120(49.2 \%)$ patients in the 7 volume-staged studies. The time to complete obliteration was reported in 4 of the 8 dose-staged studies, with a mean of 31.8 months from the last stage of SRS. The time to complete obliteration was only reported in 1 of the 7 volume-staged studies (53 months). The mean partial obliteration rates of nonobliterated AVMs for the 
Staged radiosurgery for large arteriovenous malformations

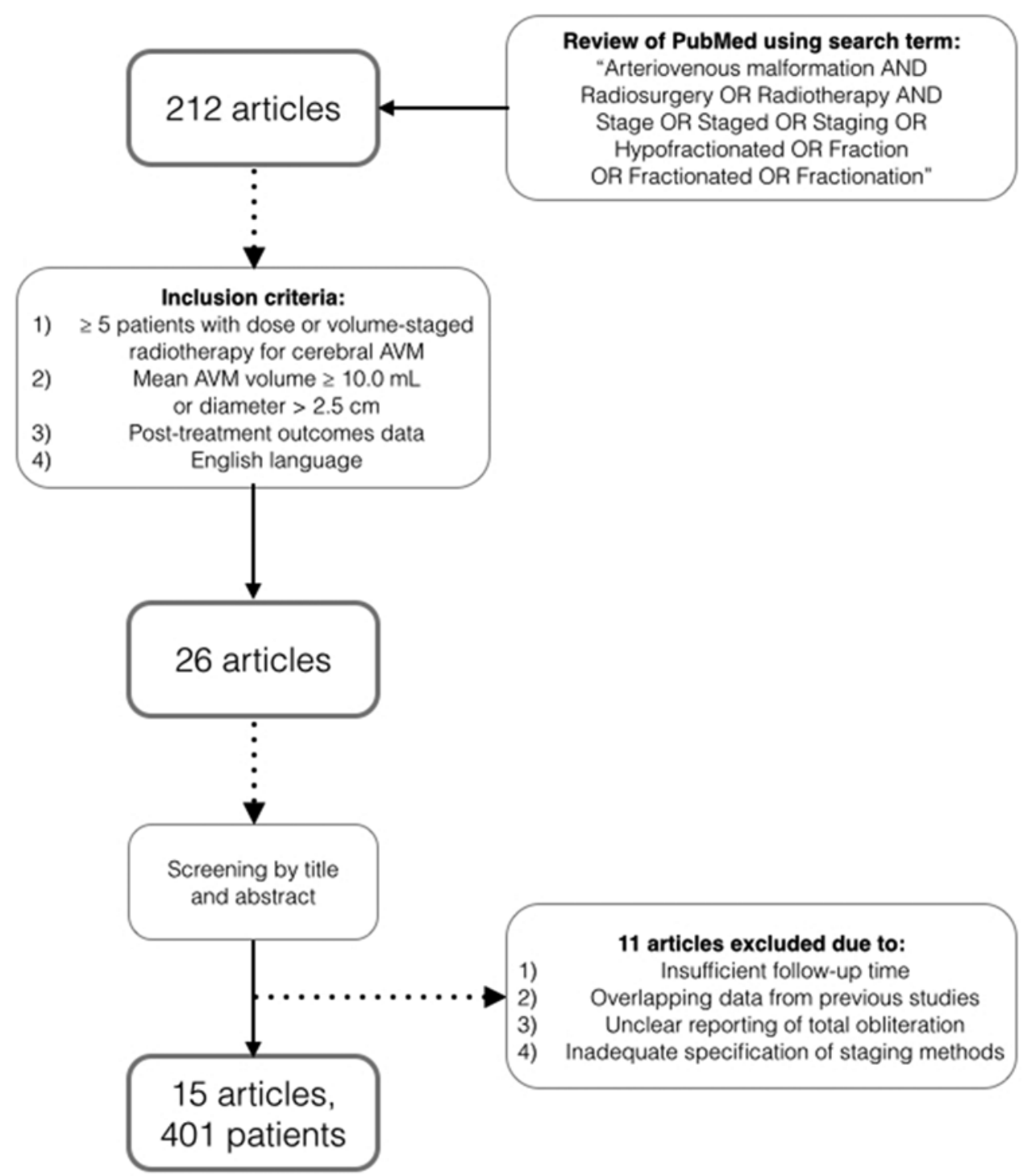

FIG. 1. Flowchart depicting the case series selection process for this systematic review. The initial PubMed search yielded 212 articles. These were subsequently screened to yield 26 articles that matched the inclusion criteria. Eleven studies were excluded due to follow-up time less than 24 months, overlapping data from previous studies at the same institution, unclear reporting of the total number of patients with complete obliteration, or inadequate specification of staging methods. Fifteen articles remained for analysis, providing data for 401 patients with AVMs treated with staged SRS.

dose-staged and volume-staged groups were $47.4 \%(95 \%$ CI $20.8 \%-74.0 \%$ ) and $83.3 \%$ (95\% CI 37.1\%-100\%), respectively. Partial obliteration of nonobliterated AVMs was demonstrated in 43 of $117(36.8 \%)$ and 22 of 47 $(46.8 \%)$ patients in the dose-staged and volume-staged groups, respectively.

\section{Complication Rates}

Radiation-induced change rates were reported in 7 of the 8 dose-staged studies, with a mean of $13.5 \%$ (95\% CI $6.7 \%-20.3 \%$ ). All 7 volume-staged studies reported RIC rates, showing a similar rate of $13.6 \%$ (95\% CI $0.20 \%-$ $27.1 \%$ ). The cumulative rate of hemorrhage was reported in all studies, with a mean of $12.3 \%(95 \% \mathrm{CI}-0.74 \%$ to $25.2 \%$ ) in the dose-staged group and $17.8 \%$ (95\% CI $12.3 \%-23.3 \%$ ) in the volume-staged group.
Mortality was reported for all studies, with a mean of $3.2 \%(95 \% \mathrm{CI}-2.3 \%$ to $8.7 \%)$ in dose-staged series and $4.6 \%(95 \%$ CI $0.37 \%-8.8 \%)$ in volume-staged series. In pooling all reported data from the dose-staged studies, 21 of $195(10.8 \%)$ patients had RICs, 25 of $223(11.2 \%)$ had hemorrhage, and 7 of $223(3.1 \%)$ died of hemorrhage. Among the volume-staged studies, 19 of $152(12.5 \%)$ had RICs, 27 of $152(17.8 \%)$ had hemorrhage, and 10 of 152 $(6.6 \%)$ died of hemorrhage. Treatment outcome summaries for the dose- and volume-staged series are presented in Tables 3 and 4, respectively.

\section{Discussion}

Explanation of Results

In this systematic review of studies implementing 
S. Moosa et al.

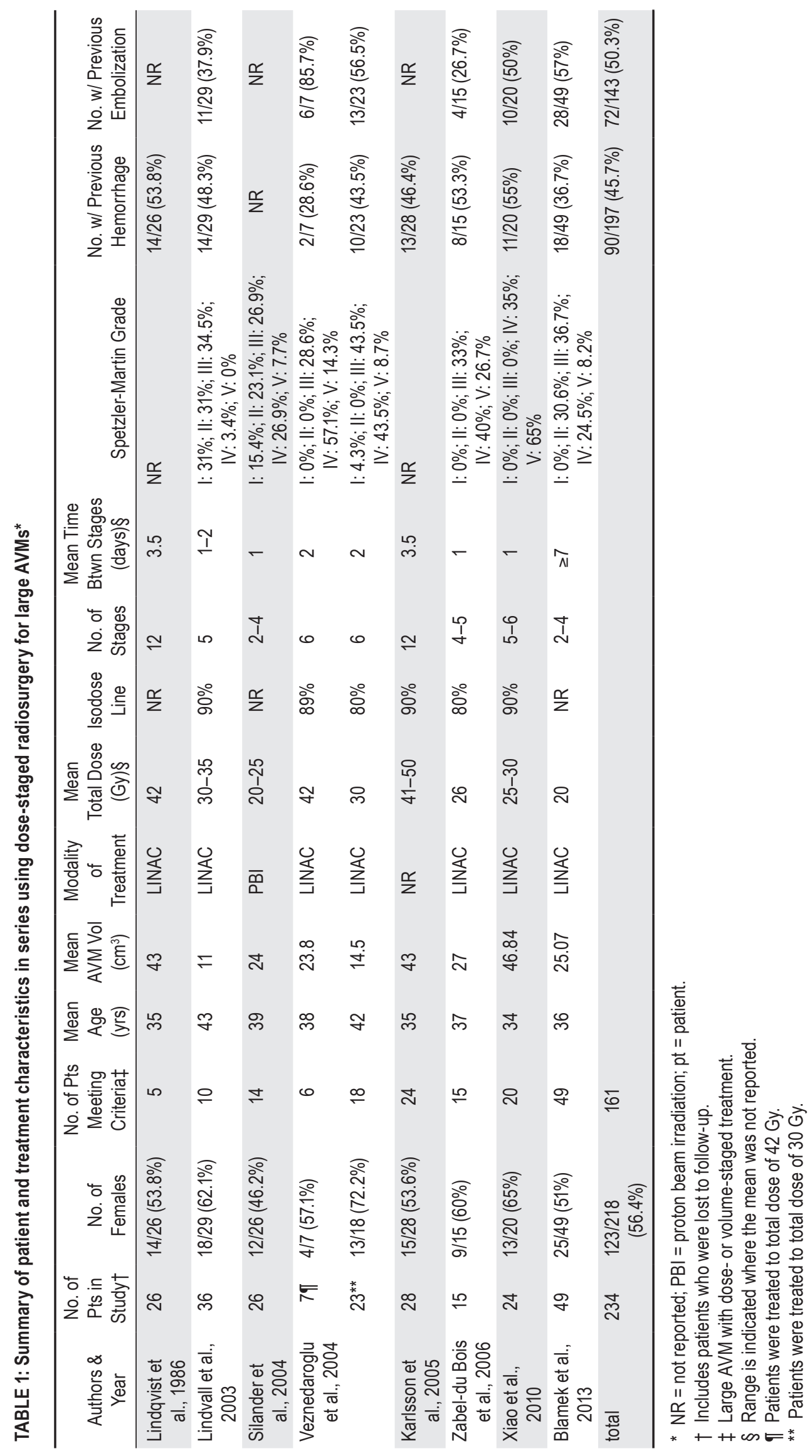


Staged radiosurgery for large arteriovenous malformations

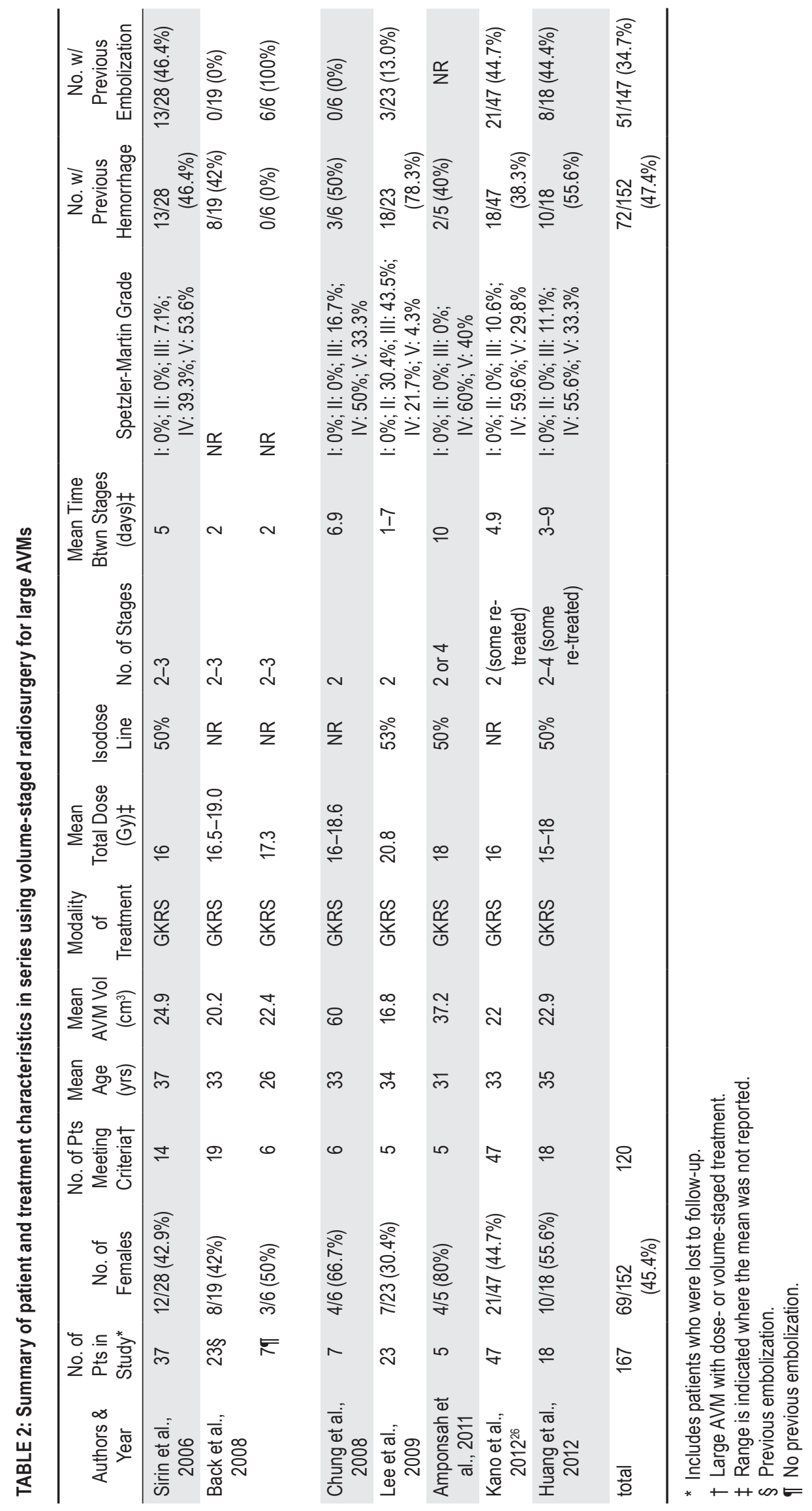


S. Moosa et al.

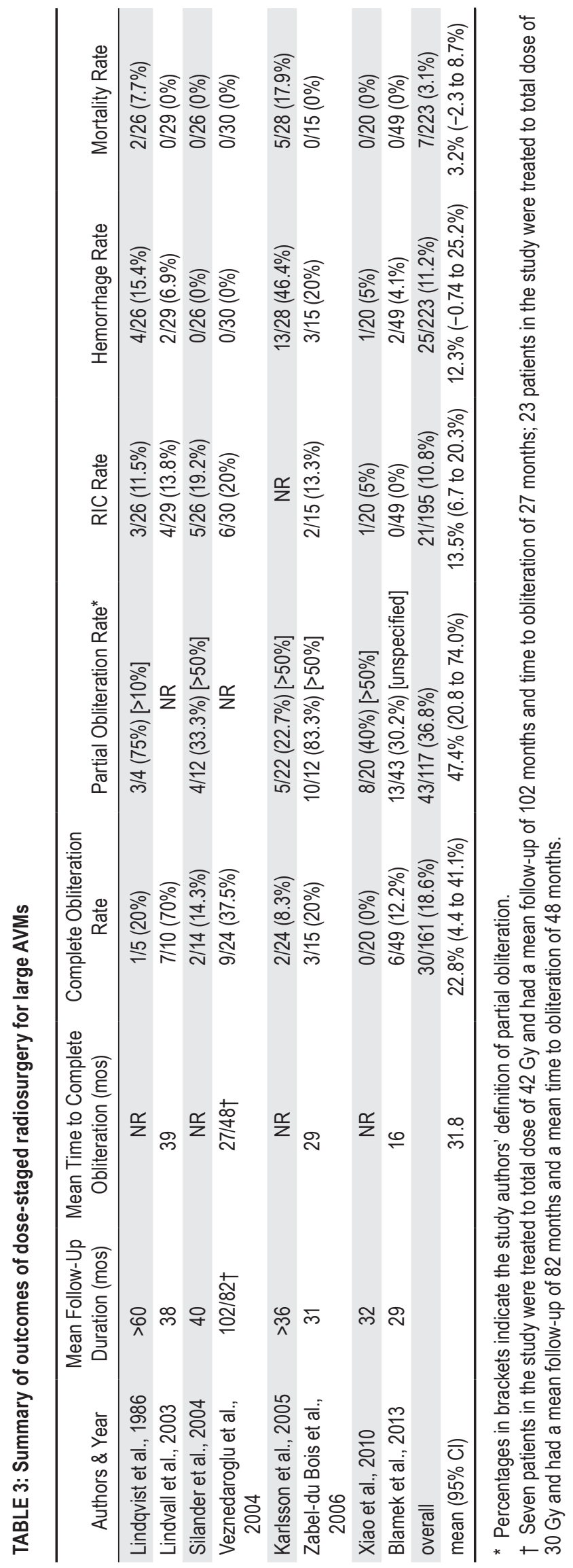

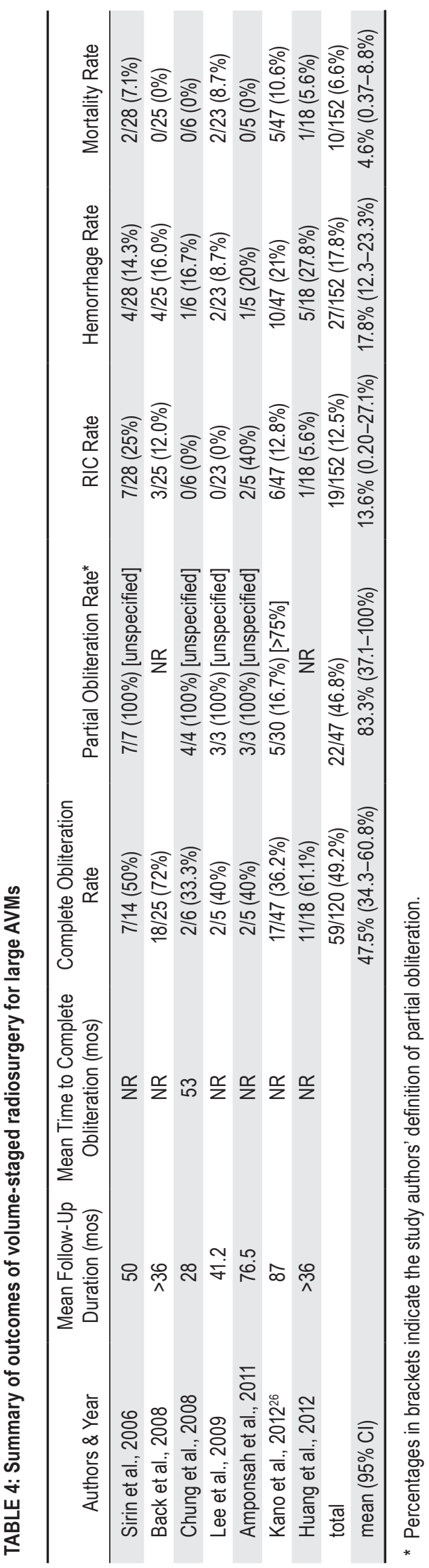

Neurosurg Focus / Volume 37 / September 2014 


\section{Staged radiosurgery for large arteriovenous malformations}

dose- and volume-staged SRS for large AVMs, we found higher mean complete and partial obliteration rates among volume-staged studies. The difference in complete obliteration rates was even more pronounced when pooled patient data were analyzed. Although the RIC rates between doseand volume-staged SRS approaches were comparable, there were slightly higher rates of hemorrhage and mortality for volume- compared with dose-staged studies when examining the mean and pooled data. Consistent with other studies that found a decreased rate of obliteration in patients with prior endovascular treatment, ${ }^{3,13,25}$ there was a higher percentage of patients with previous endovascular treatments in the dose-staged group. However, the lower obliteration rates in the dose-staged group may be unrelated to embolization-related effects and may, instead, be secondary to the manner in which SRS was delivered.

\section{Rationale for Dose- and Volume-Staged SRS}

Staged treatments have been shown to be as effective as single-session SRS with reduced complication rates. 4,27,30,40,47,52 Pollock et al. compared volume-staged SRS to hypothetical single-session procedures and found that volume staging resulted in less radiation exposure to the adjacent brain. ${ }^{39}$ Fogh et al. compared volume-staged radiosurgery to hypothetical HSRT and found that both methods have the same capabilities of sparing normal brain tissue. However, they found that HSRT studies reported in the literature treated to a higher total dosage than what was calculated to be the ideal dose for balancing efficacy and toxicity. ${ }^{18}$ Based on these findings, we would expect higher complication rates among dose-staged series, which was not the case. This may be explained by the high variability among the total dosage administered among the series included in this review. An ideal comparison of obliteration and complication rates between dose- and volume-staged radiosurgery would implement a standard total dose. It is important to note that volume staging may be inherently associated with greater risks of hemorrhage due to longer latency between treatments. Dose-staged treatments were completed in a matter of weeks, while volume-staged treatments were generally delivered over several months. While some studies have shown no change in the risk of latency period hemorrhage with partial irradiation of AVMs, ${ }^{19,28}$ others reported an increased risk, presumably from redistribution of blood flow to nontreated regions. ${ }^{11}$

\section{Risks and Benefits of Treating Large AVMs}

Microsurgical treatment of large, Spetzler-Martin Grade IV and V AVMs is associated with inherent risks; combined morbidity and mortality rates as high as $17 \%$ and $38.4 \%$ have been reported in Grade IV and V AVMs, respectively. ${ }^{20-22}$ In addition, there is an increased risk of normal perfusion pressure breakthrough with larger lesions, ${ }^{45}$ and partially treated lesions may have an increased risk of hemorrhage. Endovascular treatments have been used to shrink large AVMs prior to radiosurgery. This subsequently decreases the total amount of radiation required for obliteration. ${ }^{35}$ However, preradiosurgical embolization has been associated with not only increased risk of hemorrhage in patients without previous hemorrhage, but also decreased nidus obliteration rates with subsequent SRS. ${ }^{53}$ In a long-term, prospective, observational study of patients with unruptured AVMs randomized to interventional or medical treatment, Wedderburn et al. showed that larger AVM size was an indicator of poorer outcome in the first 3 years after intervention..$^{1,49}$ A Randomized Trial of Unruptured Brain AVMs (ARUBA) was a prospective, multicenter trial randomizing 223 patients with unruptured AVMs to medical or interventional therapy. The interventional group was shown to have a significantly greater risk of stroke and death at the mean follow-up of 33 months. ${ }^{37}$

The optimal management of large AVMs is also controversial due to an incomplete understanding of their natural history relative to smaller nidi. Direct arteriovenous shunting within an AVM creates a high-flow state prone to aneurysm formation and hemorrhage, ${ }^{6}$ with the average risk of hemorrhage estimated to be $2 \%-4 \%$ per year. ${ }^{8,12}$ Smaller AVMs typically have higher feeding artery pressures, suggesting that they have greater risks of hemorrhage. ${ }^{44}$ In contrast to this, Stefani et al. showed in a prospective trial of 390 patients with unruptured brain AVMs that larger AVM size conferred a greater risk of hemorrhage compared with small AVM size. ${ }^{46}$ In a retrospective study of 61 patients with Grade IV and V AVMs, Jayaraman et al. showed that there was an overall hemorrhage risk of $10.4 \%$ per year for these patients. This was separated into patients with and without previous hemorrhage demonstrating hemorrhage risks of $13.9 \%$ and $7.3 \%$ per year, respectively. ${ }^{24}$

It has been suggested that the benefits of treating large, Grade IV and V AVMs may outweigh the risks of treatment in certain cases the patient has already demonstrated the neurological deficits expected from excision, progressive neurological deficits attributable to steal phenomenon, associated aneurysms, intractable headaches, and/or multiple hemorrhages resulting in increasing numbers of neurological deficits. ${ }^{20,21}$ The indication for treatment of large cerebral AVMs with previous hemorrhage is supported by the study by Jayaraman et al., which demonstrated that the greatest risk reduction of hemorrhage from treatment of patients with large AVMs was in those who had presented with previous hemorrhage. ${ }^{24}$

\section{Deciding on the Best Course of Treatment for Large AVMs}

For large AVMs requiring treatment, the best course of action may include multimodal treatment with embolization, microsurgery, and/or SRS. ${ }^{9}$ Embolization may be considered to reduce the size of large AVMs, which can then be more easily treated with single-session radiosurgery. Despite the fact that prior embolization lowers the SRS-induced obliteration rate, embolization and single-session SRS may still be superior to multisession SRS. ${ }^{3,16,25}$ An alternative approach is to use initial staged SRS to reduce an AVM's volume and high-risk features, followed by repeat SRS to obliterate residual AVM. ${ }^{27}$ Our data support the use of volume-staged SRS for this purpose, as the volume-staged studies appear to afford a higher obliteration rate than dose-staged studies. Even if complete obliteration is not achieved, partial obliteration 


\section{S. Moosa et al.}

may serve to reduce neurological symptoms in patients suffering from steal phenomenon by redistributing blood flow to normal brain parenchyma.

\section{Future Directions}

Further studies are required to determine what combination of treatments provides an optimal obliteration rate while minimizing complications associated with said interventions. Ultimately, the role of staged SRS may not be to completely obliterate an AVM, but rather to initially shrink a large AVM for easier obliteration with surgical resection or single-session SRS. Additionally, technological improvements to improve the practicality and efficacy of multisession radiological treatments are also necessary. While the Leksell pin-based frame system is traditionally used in single-session SRS ${ }^{50}$ repeated placement of this device in multisession SRS is impractical and not well tolerated by patients. The Gamma Knife Extend, a noninvasive vacuum-assisted immobilization system, is one such advancement that may make multisession SRS a more reasonable treatment modality. ${ }^{41}$

\section{Limitations}

This study is limited by the significant variability of the radiosurgical parameters in the dose- and volumestaged SRS series included for analysis. Some studies also reported data on patients who underwent repeat SRS following staged treatment, which may falsely elevate obliteration rates from staged treatments. Also not all studies confirmed obliteration on angiography. While the use of MRI alone to confirm AVM obliteration has been demonstrated as a reasonable surrogate for angiography, it likely overestimates the obliteration rate in some AVM patients. Additionally, there were variations in patient and AVM characteristics between the studies, including percentages of high-grade AVMs and patients who had undergone previous microsurgical, endovascular, or radiosurgical treatments. There were also variations in the definitions of partial obliteration as well, with many studies not specifying their definitions and others having definitions of partial obliteration ranging from greater than $10 \%$ to $75 \%$ obliteration. Therefore, due to several variables that can have an effect on obliteration rates, definitive conclusion regarding the superiority of the volume-staged method compared with dose-staged method in the treatment of large AVMs cannot be made.

\section{Conclusions}

The findings of this systematic review of dose- and volume-staged treatments for large AVMs suggest that volume-staged SRS affords higher obliteration rates with similar complication rates as dose-staged SRS. The management of large AVMs, especially those that are unruptured, is controversial, and the treatment of these lesions remains challenging. While multimodal treatments including staged SRS may be beneficial, further studies are necessary to delineate the benefits of staged SRS and to evaluate new technologies for improving staged SRS.

\section{Disclosure}

The authors report no conflict of interest concerning the materials or methods used in this study or the findings specified in this paper.

Author contributions to the study and manuscript preparation include the following. Conception and design: Moosa, Chen. Acquisition of data: Moosa, Chen. Analysis and interpretation of data: Moosa, Chen, Lee. Drafting the article: Moosa. Critically revising the article: all authors. Reviewed submitted version of manuscript: all authors. Statistical analysis: Moosa, Chen, Starke. Administrative/technical/material support: Sheehan. Study supervision: Sheehan.

\section{References}

1. Al-Shahi Salman R, White PM, Counsell CE, du Plessis J, van Beijnum J, Josephson CB, et al: Outcome after conservative management or intervention for unruptured brain arteriovenous malformations. JAMA 311:1661-1669, 2014

2. Amponsah K, Ellis TL, Chan MD, Bourland JD, Glazier SS, McMullen KP, et al: Staged gamma knife radiosurgery for large cerebral arteriovenous malformations. Stereotact Funct Neurosurg 89:365-371, 2011

3. Andrade-Souza YM, Ramani M, Scora D, Tsao MN, terBrugge K, Schwartz ML: Embolization before radiosurgery reduces the obliteration rate of arteriovenous malformations. Neurosurgery 60:443-452, 2007

4. Aoyama H, Shirato H, Nishioka T, Kagei K, Onimaru R, Suzuki K, et al: Treatment outcome of single or hypofractionated single-isocentric stereotactic irradiation (STI) using a linear accelerator for intracranial arteriovenous malformation. Radiother Oncol 59:323-328, 2001

5. Back AG, Vollmer D, Zeck O, Shkedy C, Shedden PM: Retrospective analysis of unstaged and staged Gamma Knife surgery with and without preceding embolization for the treatment of arteriovenous malformations. J Neurosurg 109 Suppl:57-64, 2008

6. Batjer H, Suss RA, Samson D: Intracranial arteriovenous malformations associated with aneurysms. Neurosurgery 18: 29-35, 1986

7. Blamek S, Larysz D, Miszczyk L, Idasiak A, Rudnik A, Tarnawski R: Hypofractionated stereotactic radiotherapy for large or involving critical organs cerebral arteriovenous malformations. Radiol Oncol 47:50-56, 2013

8. Brown RD Jr, Wiebers DO, Forbes G, O'Fallon WM, Piepgras DG, Marsh WR, et al: The natural history of unruptured intracranial arteriovenous malformations. J Neurosurg 68:352357,1988

9. Chang SD, Marcellus ML, Marks MP, Levy RP, Do HM, Steinberg GK: Multimodality treatment of giant intracranial arteriovenous malformations. Neurosurgery 53:1-13, 2003

10. Chung WY, Shiau CY, Wu HM, Liu KD, Guo WY, Wang LW, et al: Staged radiosurgery for extra-large cerebral arteriovenous malformations: method, implementation, and results. J Neurosurg 109 Suppl:65-72, 2008

11. Colombo F, Pozza F, Chierego G, Casentini L, De Luca G, Francescon P: Linear accelerator radiosurgery of cerebral arteriovenous malformations: an update. Neurosurgery 34:14-21, 1994

12. Crawford PM, West CR, Chadwick DW, Shaw MD: Arteriovenous malformations of the brain: natural history in unoperated patients. J Neurol Neurosurg Psychiatry 49:1-10, 1986

13. Ding D, Yen CP, Starke RM, Xu Z, Sun X, Sheehan JP: Outcomes following single-session radiosurgery for high-grade intracranial arteriovenous malformations. Br J Neurosurg [epub ahead of print], 2013

14. Ding D, Yen CP, Starke RM, Xu Z, Sun X, Sheehan JP: Radiosurgery for Spetzler-Martin Grade III arteriovenous malformations. Clinical article. J Neurosurg 120:959-969, 2014 


\section{Staged radiosurgery for large arteriovenous malformations}

15. Ding D, Yen CP, Xu Z, Starke RM, Sheehan JP: Radiosurgery for low-grade intracranial arteriovenous malformations. Clinical article. J Neurosurg 121:457-467, 2014

16. Ding D, Yen CP, Xu Z, Starke RM, Sheehan JP: Radiosurgery for patients with unruptured intracranial arteriovenous malformations. Clinical article. J Neurosurg 118:958-966, 2013

17. Flickinger JC, Kondziolka D, Lunsford LD, Kassam A, Phuong LK, Liscak R, et al: Development of a model to predict permanent symptomatic postradiosurgery injury for arteriovenous malformation patients. Int J Radiat Oncol Biol Phys 46:1143-1148, 2000

18. Fogh S, Ma L, Gupta N, Sahgal A, Nakamura JL, Barani I, et al: High-precision volume-staged Gamma Knife surgery and equivalent hypofractionation dose schedules for treating large arteriovenous malformations. Clinical article. J Neurosurg 117 Suppl:115-119, 2012

19. Friedman WA, Blatt DL, Bova FJ, Buatti JM, Mendenhall WM, Kubilis PS: The risk of hemorrhage after radiosurgery for arteriovenous malformations. J Neurosurg 84:912-919, 1996

20. Han PP, Ponce FA, Spetzler RF: Intention-to-treat analysis of Spetzler-Martin grades IV and V arteriovenous malformations: natural history and treatment paradigm. J Neurosurg 98:3-7, 2003

21. Heros RC: Editorial. Spetzler-Martin grades IV and V arteriovenous malformations. J Neurosurg 98:1-2, 2003

22. Heros RC, Korosue K, Diebold PM: Surgical excision of cerebral arteriovenous malformations: late results. Neurosurgery 26:570-578, 1990

23. Huang PP, Rush SC, Donahue B, Narayana A, Becske T, Nelson PK, et al: Long-term outcomes after staged-volume stereotactic radiosurgery for large arteriovenous malformations. Neurosurgery 71:632-644, 2012

24. Jayaraman MV, Marcellus ML, Do HM, Chang SD, Rosenberg JK, Steinberg GK, et al: Hemorrhage rate in patients with Spetzler-Martin grades IV and V arteriovenous malformations: is treatment justified? Stroke 38:325-329, 2007

25. Kano H, Kondziolka D, Flickinger JC, Park KJ, Iyer A, Yang $\mathrm{HC}$, et al: Stereotactic radiosurgery for arteriovenous malformations after embolization: a case-control study. Clinical article. J Neurosurg 117:265-275, 2012

26. Kano H, Kondziolka D, Flickinger JC, Park KJ, Parry PV, Yang HC, et al: Stereotactic radiosurgery for arteriovenous malformations, Part 6: multistaged volumetric management of large arteriovenous malformations. Clinical article. J Neurosurg 116:54-65, 2012

27. Karlsson B, Jokura H, Yamamoto M, Söderman M, Lax I: Is repeated radiosurgery an alternative to staged radiosurgery for very large brain arteriovenous malformations? J Neurosurg 107:740-744, 2007

28. Karlsson B, Lindquist C, Steiner L: Effect of Gamma Knife surgery on the risk of rupture prior to AVM obliteration. Minim Invasive Neurosurg 39:21-27, 1996

29. Karlsson B, Lindqvist M, Blomgren H, Wan-Yeo G, Söderman M, Lax I, et al: Long-term results after fractionated radiation therapy for large brain arteriovenous malformations. Neurosurgery 57:42-49, 2005

30. Kirkeby OJ, Bakke S, Tveraa K, Hirschberg H: Fractionated stereotactic radiation therapy for intracranial arteriovenous malformations. Stereotact Funct Neurosurg 66:10-14, 1996

31. Lee SH, Lim YJ, Choi SK, Kim TS, Rhee BA: Radiosurgical considerations in the treatment of large cerebral arteriovenous malformations. J Korean Neurosurg Soc 46:378-384, 2009

32. Lindqvist M, Steiner L, Blomgren H, Arndt J, Berggren BM: Stereotactic radiation therapy of intracranial arteriovenous malformations. Acta Radiol Suppl 369:610-613, 1986

33. Lindvall P, Bergström P, Löfroth PO, Hariz MI, Henriksson $\mathrm{R}$, Jonasson P, et al: Hypofractionated conformal stereotactic radiotherapy for arteriovenous malformations. Neurosurgery 53:1036-1043, 2003

34. Liscák R, Vladyka V, Simonová G, Urgosík D, Novotný J Jr, Janousková L, et al: Arteriovenous malformations after Leksell gamma knife radiosurgery: rate of obliteration and complications. Neurosurgery 60:1005-1016, 2007

35. Mathis JA, Barr JD, Horton JA, Jungreis CA, Lunsford LD, Kondziolka DS, et al: The efficacy of particulate embolization combined with stereotactic radiosurgery for treatment of large arteriovenous malformations of the brain. AJNR Am J Neuroradiol 16:299-306, 1995

36. Miyawaki L, Dowd C, Wara W, Goldsmith B, Albright N, Gutin P, et al: Five year results of LINAC radiosurgery for arteriovenous malformations: outcome for large AVMS. Int J Radiat Oncol Biol Phys 44:1089-1106, 1999

37. Mohr JP, Parides MK, Stapf C, Moquete E, Moy CS, Overbey JR, et al: Medical management with or without interventional therapy for unruptured brain arteriovenous malformations (ARUBA): a multicentre, non-blinded, randomised trial. Lancet 383:614-621, 2014

38. Pan DH, Guo WY, Chung WY, Shiau CY, Chang YC, Wang LW: Gamma knife radiosurgery as a single treatment modality for large cerebral arteriovenous malformations. J Neurosurg 93 Suppl 3:113-119, 2000

39. Pollock BE, Kline RW, Stafford SL, Foote RL, Schomberg PJ: The rationale and technique of staged-volume arteriovenous malformation radiosurgery. Int J Radiat Oncol Biol Phys 48:817-824, 2000

40. Raza SM, Jabbour S, Thai QA, Pradilla G, Kleinberg LR, Wharam M, et al: Repeat stereotactic radiosurgery for highgrade and large intracranial arteriovenous malformations. Surg Neurol 68:24-34, 2007

41. Schlesinger D, Xu Z, Taylor F, Yen CP, Sheehan J: Interfraction and intrafraction performance of the Gamma Knife Extend system for patient positioning and immobilization. Clinical article. J Neurosurg 117 Suppl:217-224, 2012

42. Silander H, Pellettieri L, Enblad P, Montelius A, Grusell E, Vallhagen-Dahlgren C, et al: Fractionated, stereotactic proton beam treatment of cerebral arteriovenous malformations. Acta Neurol Scand 109:85-90, 2004

43. Sirin S, Kondziolka D, Niranjan A, Flickinger JC, Maitz AH, Lunsford LD: Prospective staged volume radiosurgery for large arteriovenous malformations: indications and outcomes in otherwise untreatable patients. Neurosurgery 58:17-27, 2006

44. Spetzler RF, Hargraves RW, McCormick PW, Zabramski JM, Flom RA, Zimmerman RS: Relationship of perfusion pressure and size to risk of hemorrhage from arteriovenous malformations. J Neurosurg 76:918-923, 1992

45. Spetzler RF, Wilson CB, Weinstein P, Mehdorn M, Townsend J, Telles D: Normal perfusion pressure breakthrough theory. Clin Neurosurg 25:651-672, 1978

46. Stefani MA, Porter PJ, terBrugge KG, Montanera W, Willinsky RA, Wallace MC: Large and deep brain arteriovenous malformations are associated with risk of future hemorrhage. Stroke 33:1220-1224, 2002

47. Subramanian S, Srinivas C, Ramalingam K, Babaiah M, Swamy ST, Arun G, et al: Volumetric modulated arc-based hypofractionated stereotactic radiotherapy for the treatment of selected intracranial arteriovenous malformations: dosimetric report and early clinical experience. Int J Radiat Oncol Biol Phys 82:1278-1284, 2012

48. Veznedaroglu E, Andrews DW, Benitez RP, Downes MB, Werner-Wasik M, Rosenstock J, et al: Fractionated stereotactic radiotherapy for the treatment of large arteriovenous malformations with or without previous partial embolization. Neurosurgery 55:519-531, 2004

49. Wedderburn CJ, van Beijnum J, Bhattacharya JJ, Counsell CE, Papanastassiou V, Ritchie V, et al: Outcome after inter- 


\section{S. Moosa et al.}

ventional or conservative management of unruptured brain arteriovenous malformations: a prospective, population-based cohort study. Lancet Neurol 7:223-230, 2008

50. Wu A: Physics and dosimetry of the gamma knife. Neurosurg Clin N Am 3:35-50, 1992

51. Xiao F, Gorgulho AA, Lin CS, Chen CH, Agazaryan N, Vinuela $F$, et al: Treatment of giant cerebral arteriovenous malformation: hypofractionated stereotactic radiation as the first stage. Neurosurgery 67:1253-1259, 2010

52. Yamamoto M, Akabane A, Matsumaru Y, Higuchi Y, Kasuya $\mathrm{H}$, Urakawa Y: Long-term follow-up results of intentional 2-stage Gamma Knife surgery with an interval of at least 3 years for arteriovenous malformations larger than $10 \mathrm{~cm}^{3}$. Clinical article. J Neurosurg 117 Suppl:126-134, 2012

53. Yang SY, Kim DG, Chung HT, Paek SH, Park JH, Han DH: Radiosurgery for large cerebral arteriovenous malformations. Acta Neurochir (Wien) 151:113-124, 2009
54. Zabel-du Bois A, Milker-Zabel S, Huber P, Schlegel W, Debus $\mathrm{J}$ : Linac-based radiosurgery or hypofractionated stereotactic radiotherapy in the treatment of large cerebral arteriovenous malformations. Int J Radiat Oncol Biol Phys 64:1049-1054, 2006

Manuscript submitted May 11, 2014.

Accepted May 21, 2014.

Current institution for Dr. Chivukula: Department of Neurological Surgery, University of California, Los Angeles Health System, Los Angeles, CA.

Please include this information when citing this paper: DOI: 10.3171/2014.5.FOCUS14205.

Address correspondence to: Jason Sheehan, M.D., Ph.D., Department of Neurological Surgery, University of Virginia Health System, Box 800212, Charlottesville, VA 22908. email: jsheehan@ virginia.edu. 